\title{
The alignment between the Rwandan Ordinary level national curriculum and national examinations for English: lessons for examiners \\ DOI: http://dx.doi.org/10.4314/rj.v3i1.5B
}

Emmanuel Sibomana

University of Rwanda

College of Education

Email address: siboemma14@yahoo.fr / esibomana1@gmail.com

Telephone: $+250(0) 788813624$

Abstract

This article reports on an analysis of the Rwanda national Ordinary Level curriculum for English on the one hand, and of examinations for English on the other, and the alignment between the two concepts. Textual and content analyses were conducted on the 1998 curriculum document and on the 2009, 2010 and 2011 national examinations for English. The findings suggest that the national Ordinary level curriculum and examinations for English are generally aligned especially regarding the content which they cover. However, while the curriculum recommends the development of learners' communicative competence, the examinations do not evaluate learners' listening and speaking abilities which are crucial for this type of competence. In addition, the development of critical thinking skills and abilities which are recommended by the curriculum are not accounted for sufficiently in the examinations. This situation is likely to bring teachers and learners to lay limited emphasis on the aspects which are not examined, which may produce school leavers with limited proficiency in English and higher order thinking skills.

Key words: Curriculum, assessment, constructive alignment, O'Level, examination, critical thinking

\section{Introduction}

Curriculum and assessment constitute two of the three important components of any education endeavour, the third one being teaching/learning methods, approaches and activities. These three components interact and influence one another to varying extents working together to achieve the aims of education. Explaining the relationship between these components, Biggs (1996, 2002, 2003, 2007) used a concept which he called constructive alignment. This concept ensures that an education program, the learning outcomes, teaching and learning approaches, assessment techniques, and course evaluation all complement each other (Chadwick 2004; Valsraj \& Lygo-Baker 2006).

In simple terms, Biggs indicates, constructive alignment means that all assessment tasks, and learning and teaching experiences (and therefore content and methods) must be linked to the desired unit of study learning 
outcomes. This alignment is important because these three components work for the same purpose and, therefore, reinforce one another to emphasize active student involvement in facilitated learning activities (Reaburn, Muldoon \& Bookallil 2009).

This article investigates the extent to which Ordinary level ${ }^{7}$ (O'Level) Rwandan English national examinations and curriculum are aligned together and possible implications of this alignment. In other words, it focuses on what Webb (1997) calls horizontal alignment or the "degree to which an education system's accountability assessments match content and performance standards" (Case, Jorgensen \& Zucker 2004, p. 9). While the author of this article recognizes the fact that the match is not perfect, he takes the national examinations to represent the Rwandan education system's accountability assessment while the national curriculum for English represents performance standards.

\section{Conceptual framework}

This article is framed by the concept of alignment, which is one of the two components of Biggs' (2007) constructive alignment which, according to him, starts with the notion that the learner constructs his or her own learning through relevant learning activities. This scholar suggests that this model has two aspects: (i) the 'constructive' aspect which refers to the idea that students construct meaning through relevant learning activities and (ii) the 'alignment' aspect referring to what the teacher does: to set up a learning environment that supports the learning activities appropriate to achieving the desired learning outcomes. A diagramme borrowed from Reaburn, Muldoon and Bookallil (2009) illustrates constructive alignment as follows:

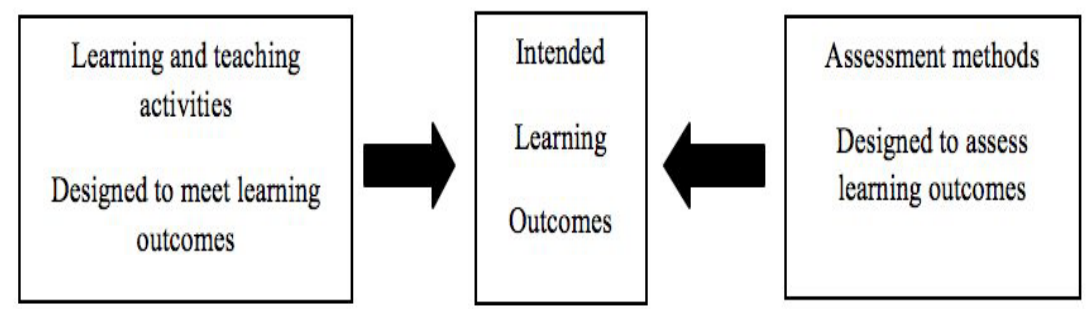

Diagramme 1: Alignment of learning activities and assessment methods to learning outcomes

As can be seen on the diagramme, the key to alignment (which is the focus of this article) is that the components in the teaching system, especially the teaching methods used and the assessment tasks, are aligned with the learning activities assumed in the intended outcomes. La

\footnotetext{
${ }^{7}$ The ordinary level means the lower secondary level which comprises of three years at the end of which learners sit for a national examination. The marks obtained in this exam are used to allocate places in the Advanced Level (the last three years) in government schools. These are cheap and are believed to provide better education than many private schools.
} 
Marca (2001) refers to this alignment as a match between test content and the subject area content. In other words, all these components must work together for the achievement of intended outcomes in such a way that "the learner finds it difficult to escape without learning appropriately" (Biggs 2007, p. 1). Constructive alignment is, therefore, an approach which optimizes the conditions for quality learning (Biggs 2003) because, among other reasons, it encourages deep learning and engagement (Jervis \& Jervis 2005; Warren 2004). Biggs (2007 p. 2) summarizes the process as follows:

In setting up an aligned system, we specify the desired outcomes of our teaching in terms not only of topic content, but in the level of understanding we want students to achieve. We then set up an environment that maximises the likelihood that students will engage in the activities designed to achieve the intended outcomes. Finally, we choose assessment tasks that will tell us how well individual students have attained these outcomes.

The concept of alignment derives from instructional design literature and emphasizes the "alignment between the objectives of a course or unit and the targets for assessing student performance" (Biggs 1996, p. 347). In the process of aligning the different components of the teaching/learning process, it appears that learning objectives play an important role. They constitute a starting point and are used to systematically align the teaching methods and the assessment (Biggs \& Tang 2009). Thus, care needs to be taken in order for learning objectives to be relevant to the context and to the intended programme outcomes.

Surgenor (2010) argues that alignment is central to effective assessment and, therefore, a clear relationship is needed between learning outcomes (or the statements of what the learner should be able to do as a result of the teaching) and assessment. According to Biggs (2007), the lack of alignment between assessment and curriculum, which may result from faulty assumptions about assessment, do more damage by misaligning teaching than any other single factor. This is because, as he goes on to argue, citing Ramsden (1992), "the assessment is the curriculum, as far as the students are concerned. They will learn what they think they will be assessed on, not what is in the curriculum, or even on what has been 'covered' in class" (Biggs 2007, p. 3).

In addition, the nature of assessment tells learners "not only what they are supposing to be learning, but how and to what standard" (Biggs \& Tang 2009, p. 2; italics in the original). This is especially the case with standardized assessments which are done periodically such as national examinations. Therefore, as Warren (2004) argues, assessment should reflect the intended learning outcomes (ILOs) contained in the curriculum so that learners (and teachers) share in the responsibility of achieving them. In this way, by preparing for the assessments, students will be learning the curriculum, hence the term 'assessment-as-learning' (Lorna 2003). Cases of misalignment of teaching and testing lead to 
considerable frustration on the part of both instructor and student because assessment does not measure what they learned (Jideani \& Jideani 2012). Thus, assessment appears to be the most important component and, as Biggs (2001) argues, if we get it wrong we get everything wrong.

After understanding the importance of alignment, one question which may arise is how to make sure that "the assessment tasks mirror the ILOs" (Biggs 2007, p. 2). In this regard, Biggs and Tang (2009, p. 4) suggest that "the key is to provide a context that requires the same action by the student that is already contained in the ILO verb(s)." In other words, assessment should show the extent to which learners have learned what they were expected to learn. In short, assessment should "mirror what you intended them [learners] to learn" (Biggs 2002, p. 6). Thus, education should not aim at achieving something and then assess something else. For instance, if the curriculum expects learners to be able to analyse a phenomenon, assessment should not expect them to describe it lest the question assesses a lower level than expected.

La Marca, Redfield and Winter (2000) identify two overarching dimensions of alignment: content match and depth match. According to these scholars, content match refers to the content that is covered; that is the breadth, range and balance of content coverage. This may be the reason why La Marca (2001) links alignment to traditional conceptions of content validity. Depth match according to Webb (1997), refers to the match between the cognitive complexity of the knowledge/skill prescribed by the standards and the cognitive complexity required by assessment tasks. In other words, this match refers to how deep the content is addressed in assessment. The concept of alignment is so important that the lack thereof is, as Biggs (1996) argues, one reason why students using rote learning as a learning strategy graduated with a first class in a system which aims at producing critical thinkers, but whose assessment approach encouraged memorization.

\section{Research methodology}

The data for this study was collected through textual analysis and content analysis. McKee indicates that textual analysis involves a process of establishing most likely interpretations that can be made of a text. In conducting this analysis I adopted McKee's $(2005$, p. 2) proposed form of textual analysis "whereby we attempt to understand the likely interpretations of texts by people who consume them." Leedy and Ormrod (2010), define content analysis as that which is typically performed on forms of human communication (such as books, newspapers, transcripts of conversations, etc.). It involves "a detailed and systematic examination of the contents of a particular body of materials" (Leedy \& Ormrod 2010, p. 144) in order to describe the characteristics of the document's content and the effect of the content on the reader, among other aspects (Bloor \& Wood 2006). 
Textual and content analyses were conducted on the 2009, 2010 and 2011 examination papers and on the Ordinary Level English curriculum document. The curriculum document which is analysed in this article was developed by the former National Curriculum Development Centre (NCDC) in 1998, before this Centre was merged with other government services pertaining to education under the Rwanda Education Board (REB). These services include the former Rwanda National Examinations Council (RNEC), whose main task was to set primary and secondary school national examinations. The RNEC is the body that set the examination papers which are analyzed in this study and these were set based on the abovementioned curriculum document.

\section{Findings}

As it has been pointed out, there is a close and mutual relationship between the curriculum, which indicates the expected learning outcomes, and examinations; the curriculum is expected to serve as a basis for the development of the examination questions. This section reports on the analysis of the two educational components and on the extent to which the O'Level English curriculum has influenced the setting of national examinations. Thereafter, the implications of this alignment are discussed.

\section{The national O'Level curriculum for English}

This curriculum document begins by presenting the general aim of teaching English in Rwanda: "to facilitate national world [sic] communication for sharing experience and for personal development"

(NCDC 1998, p. 2). That communication is the overarching aim of teaching English in Rwanda is further confirmed in the statement of the English teacher's main role, which is to help the students acquire communicative competence which will enable them to take part in activities promoting tolerance and the culture of peace (NCDC 1998). Communication is also found in what is expected of learners after the completion of the first three years of secondary school:

- Listen with understanding and speak fluently in English in a variety of contexts;

- $\quad$ Have developed the skills of reading intensively and extensively;

- Write clearly and correctly;

- Use effectively the main structures of English by writing logically and coherently on a given topic;

- $\quad$ Understanding a passage by following its content, arguments and narrative sequence and be able to infer meaning attitudes (sic);

- Use correctly and effectively a wide range of vocabulary mastered during the course;

- Demonstrate habits both in spoken and written communication;

- Relate literature to their everyday experience; 
- $\quad$ Make effective use of English in the study of other subjects in the curriculum and in the development of further learning;

- $\quad$ Appreciate the importance of English as a tool of fostering understanding among people (NCDC, 1998, p. 3).

In order to achieve the above, several content areas were selected by the curriculum designers to be addressed during these three years. These include aspects of grammar and content aimed at reinforcing the mastery of "the four skills of language learning, i.e. listening, speaking, reading and writing" (NCDC 1998, p. 2). The curriculum document contains some notes on the teaching of vocabulary but does not specify the nature of the vocabulary which needs to be acquired by O'Level learners.

The aspects of grammar are presented per year of study. In the first year, teachers are expected to teach parts of speech (nouns, pronouns, articles, verbs, adverbs, adjectives, conjunctions, prepositions, interjections), punctuation, sentence usage, tenses (present perfect, present continuous, future), direct and indirect speech, conditional tenses type 1 and 2, and comparative forms. In the second year, the aspects to be taught are tenses (past: negatives, interrogatives, passive, etc), prepositions, the use of relatives, the use of a result clause, active/passive voice, the use of comparatives, modal verbs, conditionals type 1 and 3 , direct/indirect speech, adverbs of frequency, manner and degree, the use of coordinators and linking words, and the use of concession clauses and phrases. In the third year, learners are supposed to study tenses (past perfect continuous), punctuation, advanced uses of clauses and phrases (relative and participle clauses), word formation, advanced use of countables/uncountables, and inversion of sentences (no sooner had ... than..., hardly had ... than...). However, the document does not indicate whether teachers should teach traditional or functional grammar.

Regarding the four language skills, the following is a summary of what the curriculum aims to achieve: regarding listening and speaking skills, learners are expected to be able to take part in conversations, listen and respond to live speech, make presentations such as book reports and summaries using the correct grammar, narrate stories sustaining plots and tense sequence, etc. In the writing area, learners are supposed to be able to write descriptive, narrative, discussion/argument texts, summaries and reports. As for reading, they are expected to read for understanding, inferring the meanings of unfamiliar words and expressions from the context, to perceive deeper meaning and the effect of punctuation on meaning, recognize the register, etc. In addition, learners are expected to be able to apply critical thinking to what they read by distinguishing fact from opinion and judging the opinion.

The curriculum document also recommends that at least three books selected from novels, plays and poetry should be read per year. In addition to these literary texts, the document lists very few literature related aspects and texts to be used as teaching/learning resources (not as content to be taught) in the third year. These are easy novels, writing 
exercises on drama, riddles, proverbs, tongue twisters and creative writing. While the curriculum aims to enable learners "to relate literature to their everyday experience" (NCDC 1998, p. 3), it does not recommend the teaching of any literary genre.

Thus, it is not clear how learners can be helped to relate literature to their experience while it is not taught to them explicitly. Another important thing to note is that there is no indication of the time allocated to different content areas within the curriculum. Time allocation, according to Singh and Harris (2010), gives an idea of what teachers should foreground and/or back-ground. Nevertheless, based on the details that are provided for different content areas in this document, it can be argued that grammar occupies a major part. For instance, while for other types of content only objectives and learning activities are mentioned, topics and subtopics (sometimes accompanied by examples) are provided for every aspect of grammar to be taught. In spite of the big space allocated to grammar, there is no indication on what type of grammar (traditional or functional) needs to be taught.

\section{The national O'Level English examinations}

The national O'Level examination for English is three hour long. It carries 100 marks and is made up of four sections: Comprehension and Vocabulary (30 marks), Grammar and Phonology (45 marks), Summary writing (10 marks) and Composition (15 marks). Grammar has the biggest share in the O'Level national examination for English: out of the 100 marks, grammar is allocated 35 marks in 2009, 40 marks in 2010 and 35 marks in 2011.

The comprehension part generally consists of a one and a half to two page text and multiple choice comprehension questions with four answer options each. It also has a limited number of questions requiring either answers in own words (for 2009 and 2011) or those requiring true or false types of answers (2010). The fact that the answer options have been provided and are very short suggests that related questions evaluate communication to a very limited extent. The vocabulary part provides a list of words from which learners have to choose the correct word to fill in the gaps left in passages (2009 and 2010) or in sentences (2011). Nevertheless, this part appears relatively more communicative and expects learners to think more deeply as it requires the use of the terms in a context. For instance, the following is the vocabulary question in the 2009 examination paper:

Choose from the list below an appropriate word or phrase to complete the following paragraph: Meet, clubs, similar, deal, shy, imagine, a few, devoted, among, least.

Britain is a land of ..... and societies and a large number of people belong to at ..... one society. These organizations hold regular meetings, which take up a good ..... of time; they make it very simple to ..... others with ..... interests. The British, being rather ..... , feel more at ease when 
they are ..... people with whom they have something in common. There are so many different societies that it is difficult to ..... a person who could not find one single one to interest him. There are societies ..... to music, art, discussion, photography, amateur drama, bridge, chess and bowling to name only .....

In order for learners to answer this question effectively, they need to reflect not only about the provided words but also about the context in which they are used; that is the meanings of other words, the way sentences are constructed, the meaning of the whole passage, etc. This reflection may enable them to recognize the same structures in novel contexts (see Biggs 1996).

The grammar section includes a large number of multiple choice questions, asking learners to choose a correct structure that fits in the gap left in sentences. For instance, out of 35 marks allocated to grammar in 2009,25 are allocated to multiple choice questions, and such questions account for 20 of the 40 marks in 2010 and 15 out of 35 marks in 2011. The following are examples of such questions:

1. Mary wouldn't let him ....

a) to dance with her b) dance with her c) dancing with her d) dance her (2010).

2. Our house ... ten years ago.
a) was built
b) built
c) would be built
d) had

been built (2009).

In the phonology section, learners are provided with four words for each question, with one word having a different sound or stress (e.g. bear, fear, wear, dare - 2010; necessary, knowledge, police, benefit - 2011), and are asked to identify the word. For summary writing, learners are asked to summarize a short text that is provided (2010 \& 2011), or a passage from the reading comprehension text (2009). With reference to composition, learners are given three topics from which they have to choose one and write an approximately 200 word descriptive or argumentative essay. The following are some of the topics: 'Life in the countryside is better than in the city'. To what extent do you agree or disagree with this statement? (2009); Write an account of your favourite personality in sport and state why you admire him/her (2010); A friend of yours who lives in England wants to come to visit Rwanda. Describe to him/her your country, its beauty and places he/she should visit while in Rwanda (2011).

This brief overview indicates that comprehension and grammar constitute a major part of these examinations. These two parts of the examination evaluate learners' ability to communicate in English to only a very small extent in spite of communication being the overall aim of teaching English in Rwanda (NCDC 1998). In fact, the questions do not encourage learners to formulate answers in their own words and/or to think from various and different perspectives. The following multiple 
choice reading comprehension question (on a text about the United Nations) in the 2010 examination illustrates this point:

Question: Why was the UN established?

\section{Answer options:}

a) To help prevent wars between nations

b) To rule the world

c) Because representatives from rich countries approved the charter

d) To end all the wars

To some extent, this question evaluates learners' understanding of the text, but it could have done more if learners had been allowed to answer using their own words. This could have given them more options and freedom to show their ability to use the language. In addition, given that learners are provided with clues in the form of answer options, ticking the right answer does not necessarily guarantee that learners understand the text and can justify their thinking. In fact, the question evaluates how well the task has been performed (see Biggs \& Tang 2009) or the end result, but does not assess and/or provide for the thinking behind the answer.

This thinking could involve various tasks carried out with varying degrees of success but which have not been recognized and/or rewarded. Further, it does not encourage deep thinking because, Biggs (1996) argues, such answers (one word, phrase or brief sentence answers) are unlikely to elicit high level engagement from learners. Therefore, letting learners answer using their own words could have been a better alternative, which implies that learners would have been evaluated not just in terms of whether their answers were right or wrong but also in terms of whether they were thinking in the right direction. In other words, the answers 'rightness' and/or 'wrongness' could have been gradable.

Concerning grammar, fill-in gap types of questions do not necessarily guarantee learners' ability to use the examined aspects and/or rules in context or to formulate the suggested phrases themselves. Nevertheless, there are a very limited number of questions that test learners' ability to use grammar in context. These include using correct tenses (e.g. He said that if he had money he (buy) me a drink -2011; Mary (be) sick in hospital for a month -2010); correcting sentences (How Mary did travel to Kigali? -2011); rewriting sentences according to given instructions (It's a pity there is no secondary school in my village: rewrite using $I$ wish...... -2009), etc. If the entire grammar section was made up of such questions, especially in a continuous text (as in the 2010 exam paper) instead of discrete sentences it could have better shown learners' abilities to use grammar in meaningful contexts. 


\section{Discussion of the alignment}

From the above description of the O'Level national curriculum and examinations for English, it can be argued that these are generally in alignment with each other especially in relation to the content match (La Marca, Redfield \& Winter 2000). Apart from speaking and listening areas, all other content areas in the curriculum are covered by national examinations. With reference to content weighting, grammar occupies considerable space in the two documents. This finding suggests that those who set the examination papers understood that "care has to be taken that the weighting of the assessment task is appropriate in reflecting the relative importance of the Unit ILOs" (Biggs \& Tang 2009, p. 6). However, the curriculum document itself does not make any reference to using the various grammatical structures to express different meanings in different contexts as an end aim, which may be the reason why the examinations themselves focuses on formal rather than functional grammar.

Nevertheless, the alignment is wanting regarding the depth at which the content is addressed or the aforementioned La Marca, Redfield and Winter's (2000) depth match. This is because some content areas are not addressed in the examinations as deeply as required by the curriculum. For instance, while learners are expected to apply judgmental/critical thinking to what they read, the examinations hardly examine these skills. Apart from argument essay writing (which is optional and not always included), the three papers which were analysed include only two comprehension questions (in 2011) which appear to encourage learners to think critically and express their opinion: (i) How do you think the bride felt as she was waiting for the groom to arrive?" and (ii) "Do you think the women were fair to the two men?" Thus, critical thinking appears to have been overlooked if not neglected.

The author of this article acknowledges the difficulty of setting questions that require or encourage the expression of own opinions especially when the marking has to be standardized and 'multiple markers' (Biggs 1996) are involved. However, he argues that at least some questions (maybe few) should be included in each paper. This is more so because the Rwanda Education Board has introduced a competency-based curriculum to optimize "the potential of all learners and enabling every young Rwandan to make a valuable contribution to the sustained growth of the nation" (REB 2015, p. 3). In order to achieve this vision, REB (2015) indicates that the curriculum will provide challenging and engaging learning experiences which require deep thinking rather than just memorization and, the author suggests, this needs to be reflected in assessment.

It has been noted earlier that listening and speaking are not assessed in the national examinations for English not only for the O'Level but also 
for the Advanced level (end of secondary level) examinations ${ }^{8}$. This is a cause for concern because the two skills and related knowledge not only play an important role in communication, but are the basic language skills which many language users rely on. Therefore, the ability to use language in a written form, which is the focus of the examinations, does not necessarily imply the ability to use the language to engage in dialogue with others by listening "with understanding and speak fluently in English in a variety of contexts" in order to promote the culture of peace as recommended by the curriculum (NCDC 1998, p. 3).

Failure to examine learners' speaking and listening skills and knowledge may bring learners and teachers to neglect the teaching and learning of these areas. This is because, as has been pointed out earlier, assessment constitutes the curriculum for learners and these structure their learning activities on the basis of assessment (Warren 2004). Further, Rwandan schools are ranked and teachers' teaching competence evaluated based on their learners' performance in national examinations. Moreover, the curriculum identifies good performance in the examination as one of the objectives of teaching English (NCDC 1998).

Thus teachers are likely to teach to examinations, focusing on those aspects which occupy considerable space in the curriculum and, therefore, the areas which are not examined (for example speaking and listening) may receive limited or no attention from teachers. Indeed, some teachers who participated in the author's study of the University of Rwanda's language teacher education programme at a distance indicated that they focused on grammar rules in their classes because it occupies considerable space in the national examinations (Sibomana 2014). This exam-focused teaching may lead to learners' communication skills being hampered, making them knowledgeable about grammar but with limited competence in using it generatively in daily communication. In order to address this limitation, Rwandan education policy makers should think of ways to assess learners' oral and aural abilities in national examinations so that they test the very outcomes they want students to achieve (see Warren 2004). However, it is worth acknowledging that this endeavour is difficult but possible. The University of Rwanda's College of Education could serve as an example because it examines listening and speaking abilities of the Advanced Level candidates from Teacher Training Colleges.

\section{Conclusion}

This article has presented an analysis of the Rwandan national O'Level curriculum document, of the 2009, 2010 and 2011 examinations for

\footnotetext{
${ }^{8}$ The exception is only for the candidates from Teacher Training Colleges whose examination is carried out by the University of Rwanda's College of Education. Their examinations include an oral-aural component which is done by a panel of examiners.
} 
English and of the alignment between the two documents. The analysis has indicated that the two documents are not completely aligned to each other. While the curriculum document states that using English for communication is the main intended learning outcome, the document just indicates the content areas to be covered but does not indicate how teachers can help learners to use these to communicate. The examinations themselves assess learners' ability to communicate to a very limited extent notably because multiple choice questions are given prominence, which limits learners' use of own words to formulate answers.

Furthermore, speaking and listening skills and knowledge, which are part of the curriculum, are not assessed. Critical thinking, which is also recommended in the curriculum, is not encouraged in the examinations. Given that learners and teachers tend to teach and learn to the exams, the areas which are not covered by the assessment are likely to be neglected by both teachers and learners. This situation is likely to prevent the education system from achieving the intended teaching/learning outcomes. Since teaching and learning activities and approaches (as one component of constructive alignment) have not been analysed in this study, further research could investigate the extent to which this component is aligned to the two components which have been discussed in this article.

\section{References}

1. Biggs, J 1996, Enhancing teaching through constructive alignment, Higher Education, vol. 32, pp. 347-364.

2. Biggs, J 2001, On constructive alignment. Background notes to support a seminar given by Prof John Biggs to support a seminar on the topic the University of Edinburgh on July $3^{\text {rd }}$ 2001.Viewed 07 December 2015 from http://www.essentialgptrainingbook.com/resources/chapter_29/O n\%20Constructive $\% 20$ Alignment $\% 20$ by $\% 20$ John $\% 20$ Biggs.pdf.

3. Biggs, J 2002, Aligning the curriculum to promote good learning. Paper presented at the Constructive Alignment in Action: Imaginative Curriculum Symposium. Monday, $4^{\text {th }}$ November.

4. Biggs, J 2003, Aligning teaching and assessment to curriculum objectives. Learning and Teaching Support Network. Viewed $\quad 05 \quad$ November 2015 from https://www.heacademy.ac.uk/sites/default/files/biggs-aligningteaching-and- assessment.pdf,

5. Biggs, JB 2007, Aligning teaching for constructing learning. The Higher Education Academy. Viewed 10 May 2014 from www.heacademy.ac.uk.

6. Biggs, J \& Tang, C 2009, Applying constructive alignment to outcomes-based teaching and learning. Viewed 08 December 2015

from 
https://intranet.tudelft.nl/fileadmin/Files/medewerkersportal/TB M/Onderwijsdag_2014/What-is-ConstructiveAlignment.pdf.

7. Bloor, M. and Wood, F 2006, Keywords in Qualitative Methods: a Vocabulary of Research Concepts, Sage Publications: London.

8. Case, BJ, Jorgensen, MA \& Zucker, S 2004, Alignment in Educational Assessment. Pearson Assessment Report. Viewed $01 \quad$ November 2015, http://images.pearsonassessments.com/images/tmrs/tmrs_rg/Alig nEdAss.pdf?WT.mc_id=TMRS_Alignment_in_Educational_Ass essment.

9. Chadwick, SM 2004, Curriculum development in orthodontic specialist registrar training: can orthodontics achieve constructive alignment? J Orthodon, vol. 31, pp. 267-274.

10. Jervis, LM \& Jervis, L 2005, What is the Constructivism in Constructive Alignment? BEE-j, 6. Viewed 05 June 2016 from http://www.bioscience.heacademy ac.uk/ journal/vol6/ Beej-6-5.pdf.

11. Jideani, VA \& Jideani, IA 2012, Alignment of Assessment Objectives with Instructional Objectives Using Revised Bloom's Taxonomy-The Case for Food Science and Technology Education, Journal of Food Science Education, vol. 11, pp. 34-42.

12. La Marca, PM, Redfield D \& Winter, PC 2000, State Standards and State Assessment Systems: A Guide to Alignment, Council of Chief State School Officers: Washington, DC.

13. La Marca, PM 2001, Alignment of standards and assessments as an accountability criterion. Practical Assessment, Research \& Evaluation, vol. 7, no 21. Viewed 03 June 2016 from $h t t p: / / p a r e o n l i n e . n e t / g e t v n . a s p ? v=7 \& n=21$.

14. Leedy, PD \& Ormrod, JE 2010, Practical research planning and design $\left(9^{\text {th }}\right.$ Ed), Pearson: Upper Saddle River.

15. Lorna, E 2003, Assessment as Learning: Using Classroom Assessment to Maximise Student Learning. Corwin Press: Thousand Oaks, CA.

16. McKee, A 2005, Textual analysis: a beginner's guide. Sage Publications Ltd, London, California, New Delhi.

17. National Curriculum Development Centre 1998, Ordinary Level English Programme for Anglophone, Kigali.

18. Reaburn, P, Muldoon, N \& Bookallil, C 2009, Blended spaces, work based learning and constructive alignment: Impacts on student engagement. Proceedings ascilite Auckland, pp. 820-831.

19. Rwanda Education Board 2015, Competency-based curriculum: Summary of curriculum framework pre-primary to upper secondary, Kigali, Rwanda.

20. Surgenor, P 2010, Constructive alignment: Teaching toolkit. UCD teaching and learning resources, Viewed 01 
December

2015

from

http://www.ucd.ie/t4cms/UCDTLT0028.pdf.

21. Valsraj KM, Lygo-Baker, S 2006, A balancing act: developing curricula for balanced care within community psychiatry. Advances in Psychiatric Treatment, vol. 12, no 1, pp. 69-78.

22. Warren, H 2004, Engineering subject centre guide: Learning and teaching theory for engineering academics, HEA: Engineering Subject Centre: Loughborough.

23. Webb, NL 1997, Determining alignment of expectations and assessments in mathematics and science education. NISE Brief, vol. 1, no 2. Viewed 07 December 2015 http://archive.wceruw.org/nise/Publications/Briefs/Vol_1_No_2/ 